\title{
Between project efficiency and stakeholders' interests: project intake decisions in nonprofit organizations
}

\author{
Ibrian Caramidaru $^{1 *}$, and Andreea Ionica $^{1}$ \\ ${ }^{1}$ University of Petrosani, Str. Universitatii nr.20, Petrosani, Romania
}

\begin{abstract}
Nonprofit organizations implementing their strategies through multi-project environments are perennially confronted with the difficulties embedded into their institutional design. Assessing the social results is intrinsically dependent on the missional depiction of social change and it is to be performed in settings of project networks influenced by multiple stakeholder interests. In order to balance the project efficiency, in terms of the triple constraint of scope-time-budget, and the need for stakeholder satisfaction, when it comes to project intake decisions a procedural decision making approach is required. The aim of this paper consist in proposing a decision making process and the adjacent procedures set for project intake decisions guided by various criteria. This process takes into account: mapping the stakeholder's importance and influence on strategy casting, assessing the social outcome of projects and project efficiency requirements.
\end{abstract}

\section{Introduction}

Plenty of research has been done lately both on nonprofit organizations and on multi-project management, however not much effort was committed to studying how the peculiarities of nonprofit behaviour are to be linked to the issues unfolded by multi-project practices. The capacity of nonprofit organizations to design multiple projects requires a method of comparison between alternative projects competing for a restrictive pool of resources. The comparisons between project could be performed ex-ante (for project selection decisions), during the project execution (for monitoring processes) or ex-post (for project implementation appraisal) [1]. Resource scarcity and strategic fit are the main limits to project intake decisions.

Supplying several definitions of nonprofit organizations and their multi-project environment is required from the outset. In the context of this paper, a nonprofit is defined as an organization characterized by a restriction of non-distribution of profits (through dividends or managerial wages) [2]. This definition is broad enough to capture different organizations under the same concepts, encompassing the charitable/voluntary sector, nongovernmental organizations, social businesses and civil society organisms. By the multiproject environment, we mean organizations that supply their outputs through a network of inter-related projects, hence the multi-project dimension encompasses project based-

* Corresponding author: ibrian.caramidaru@gmail.com 
organizations, portfolios or programs, which cannot be explained in terms of merely an aggregation of disparate projects.

In order to comprehend the specifics of project management in nonprofit settings and the its peculiar constraints, one can start from practical questions on the purpose of a particular project, both in the short and long runs, and on how the organization is meant achieve this purpose. The literature on the evaluation of public and non-profit programs [3] considers that a first step in identifying an appropriate measure for project success is to identify a logical model leading from project means, to project deliverables and, eventually, to the social impact or outcome of projects in long run. The description of a causal relationship between deliverables and social outcomes requires their simultaneous consideration, as part of a scoring function for substantiating project intake decisions, of the means and control variables of the project.

The aim of this paper consist in proposing a decision making process set for project intake decisions guided by various criteria, in order to balance the project efficiency, in terms of the triple constraint of scope-time-budget, and the need for stakeholder satisfaction. The structured process of strategic project intake decisions, consists in manipulating project proposals through four main procedural steps informed by endogenous and exogenous data. The following sections present the background and methods of the research, the specifics of nonprofit strategic management affecting the project selection process and the proposed process itself, while stressing throughout that the proposed selection process (encompassing the design of a score function for project intake decisions) should take into account: the net value of the results for the beneficiaries, on the one hand, and how these results were achieved in terms of reaching the project objectives and timelines. Thus, a convergence framework can be created between the utility value for the beneficiaries and the organizational effort to obtain these results, which, in our case, respects the logic of the model of obtaining the social results by moving from How to Why projects are selected and implemented.

\section{Background and method}

The literature on customized nonprofit tools and techniques for ex-ante project assessment is relatively scarce, an exception is represented by the fact that some indicators meant to measure social impact could also be forcasted for future alternative projects [4]. Also, with a few notable exceptions $[5,6]$, the issues related to project portfolio management are not usually customized to suit nonprofit management.

The suggestion and application of putting together, in a synthetic score function or in a project selection methodology, of the project contributions (results and outputs) and the project efforts (through constraints and inputs), has already been proposed by different authors form various backgrounds and through various means, such as: a hierahical decision model [7], a data envelope analysis for project efficiency comparisons [8] or a multi-objective algorithm for project selection [9]. Only the first proposal mentioned above [7] is actually tailored for nonprofit project selection decisions and it offers a model that mainly helps identifying the projects aligning with the organizational mission, from the point of view of one category of stakeholders. Some of the aims of recent studies on multi-criteria analysis consist in diminishing the number of criteria (grouping similar criteria and neglecting some of them), escaping a complex weighting procedure or searching for decisional procedures which do not require very complex organizational change for the decision model to be implemented [8].

The research question can be formulated as follows: How can nonprofit organizations select projects under the requirements of stakeholders, while complying with the project constraints? 
To answer this question, we draft a prototype for the process of project intake decisions entailing the steps grounded in the relevant literature and proposing a score function in the final step of the process. In order to use the proposed score function, each project proposal should supply information on: the stakeholders pertaining to the project, the list and values of project outcomes, the list of project inputs and their associated costs, the flexibility of the triple constraint elements, the statistical values for delivery and schedule efficiency. To ensure the comparability of the information provided and the various aggregation of similar information, the organization should have in place homogenous project management tools and practices for estimating and reporting on the triple constraint compliance and social outcomes yielding. In terms of the triple constraint flexibility, the historical statistical efficiency would serve for informing the management on whether the organization could comply with the rigid requirements of the financers. In multi-criteria analysis the weights of the criteria represent the trade-offs achievable between the magnitudes of the compliance with the criteria, in our prototype the only weighting system used is the average time preference for the output, whereas the project efficiency ratios are pointing not to the value itself of the project, but rather to the probability of the project completion within the established project constraints.

\section{Strategical issues in nonprofit multi-project management}

The nonprofit organizational setting advances different metaphors to portray the aptitude for fit of the projects into a coherent whole, metaphors aimed at instilling meaning into current actions and building up an organizational narrative (amidst which the mission formulation is preeminent) [10].

The nonprofit mission and vision, driven by a set of moral values, are an expression of the organizational societal approach. In order to delineate a linkage between the organizational mission and the project, the board and management of the nonprofit have to establish means to operationalize the mission, through arrays of goals and corresponding metrics. This would facilitate the monitoring processes of project management, ensuring that the project contribution to the fulfilment of the organizational mission is made transparent and trackable. This typical scenario usually portrays organizations as being a multi-level unfolding of structures that are the result of strategy and of the rules of governance. In their own turn, these basic guidelines (strategy \& governance) provide a framework for project management [11]. This script is not followed anywhere precisely as described above, being aptly called utopian [12] The nonprofit mission already entails the view of peculiar stakeholders on what society is and what needs are more salient for the founding members and their recurrent donors. However, this shared understanding does not obey a necessary logic of top-down mission alignment, but rather exhibits a two-way track, where projects activities also influence strategy [13], defying the common perspective of projects seen as mere sites of strategy implementation [14].

A very significant contribution of stakeholder theory to nonprofit institutional design consists in its ability to point to the elusive organisational boarders. Answering the perennial question of organizational constituency has to be an ongoing process for nonprofits, rather than a trivial matter of referring to the statutes and by laws of these entities [15]. As one author puts it, in nonprofit strategic management , the objectives that are perceived as important and pursued at any time are very dependent upon the relative power of the influencers and their ability to exercise power." [16]. The three main categories of nonprofit stakeholders are their beneficiaries, their boards and their donors. The donors of nonprofits are not only the stakeholders supplying the financial streams ensuring organizational perpetuity, but their influence and pressure could lead as far as mission displacement. The peculiarities of the process of project selection in nonprofits are given by the financing 
structure of these entities, the stakeholder accountability requirements and their generic nonprofit mission orientation, which makes it difficult for social results to be measured. The model for project portfolio adapted to nonprofits, and proposed by [5], specifically inserts the fundraising dimension (with its element of stakeholder accountability). It is significant that some methodologies of measuring social impact are also relying on a solid ground of social accountability standards and principles. As some authors have shown $[17,18]$ the success of projects is highly determined by the consensus of the parties affected and affecting the project life cycle. The transparency of project selection procedures increases also organizational legitimacy, an aspect highly influential for nonprofits serving the public. There exists a certain funding competition for nonprofit projects, and, in this venue, the value of financing represents the price of the project as a process - the project being aimed at through the financing decision as means to obtain the desired deliverables and social outcomes.

As already alluded, another nonprofit characteristic bearing on strategic management consist in the difficulty to measure social outcomes. A number of methodologies have been proposed for measuring social impact $[4,19]$. These methodologies involve a social theory of change connecting project activities to social outcomes. Social outcomes being measured using financial proxies for saved social expenses or shadow prices for similar marketable products. Finding an instrument for assessing social impact is of paramount importance for nonprofit strategic management, but the social impact dimension should be paired with other indicators of organizational health, resulting in dashboards or balanced scorecards adapted to the managerial needs of nonprofits.

\section{A project intake decision making process in multi-project nonprofits}

The present paper offers a structured process of strategic project intake decisions, the process, represented in Figure 1, consists in manipulating project proposals through four main procedural steps informed by endogenous and exogenous data. The representation is Figure 1 is using the following conventions: the project stocks are depicted as circles, the steps of the project selection process are represented by squares, the flow of project proposals and the information flows are depicted by continuous and dotted arrows respectively.

The organization could harvest project ideas, producing a pool of project blueprints at hand in case financing and resources become available. A threshold should be established to discern whether small projects (in terms of duration and the resources employed) should move on to operational initiation, rather than be a part of a strategic selection procedure. The project set generated by an organization is informed on one side by the internal ideas and, on the other side, by the financing opportunities. Running projects for the main reason that financing resources are available could be regarded as opportunistic, but nonprofit management has to deal on a regular basis with balancing short term survival with long term sustainability, being hence, at times, press to adapt projects which are marketable to the financers [15]. This aspect puts an additional pressure on project intake decision makers, since refusing a financing opportunity for a project could lead to competitive advantage of other nonprofits competing for the attention of similar donors and social causes.

Before being analysed through the computation of the score functions some projects shall be excluded from the outset, an exclusion which is performed on two levels - the strategic and the portfolio level. 


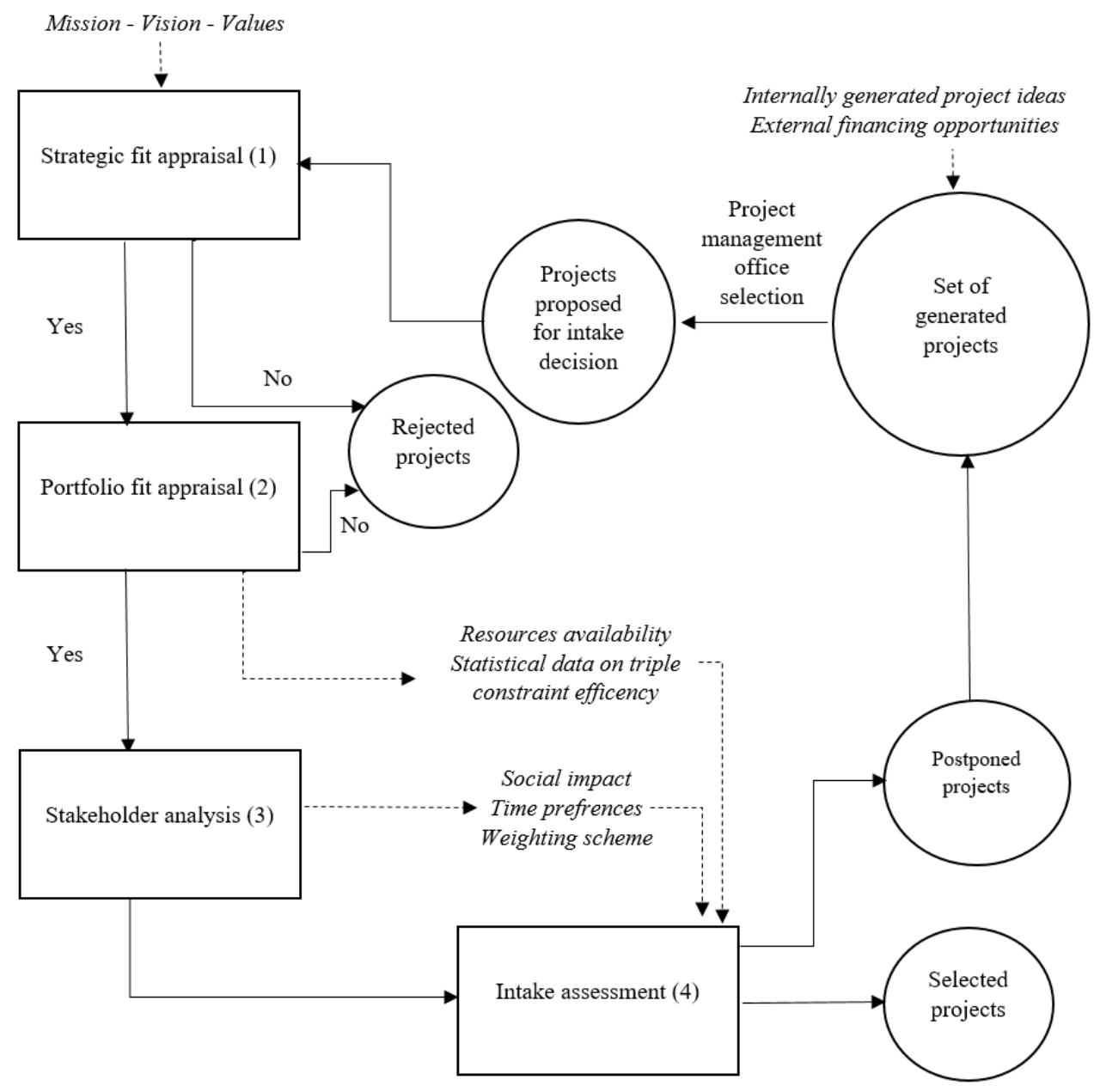

Fig. 1. The strategic process of project intake decisions

At the strategic level - in step (1) - Strategic fit appraisal - a hierarchical decision model (as in [7]) could be used, guided by an analysis pointing to the agreement (or lack thereof) between the project goals and the organizational strategic mission, vision and values. The strategic fit appraisal of projects should take into account the organizational capability for the project fundraising management (referring to the processes of fundraising planning, fundraising coordination and funding agreement completion [5]). In order to facilitate the comparison of the projects through the lenses of strategic fit, a binary approach might be employed pairing the projects by alternative relations of preference, equivalence and indifference [1].

In step (2) - Portfolio fit appraisal - the goal of the portfolio fit appraisal is not commit the organization to projects for which, at least momentarily, there are not enough resources and capabilities. If a project is accepted as strategically fit, it should be assessed in terms of its fit for inclusion into the organizational portfolios, this shall be done mainly in terms of the magnitude of the resources and the know-how required for the project implementation. At this level, the statistically derived average ratios of execution and time efficiency for similar projects embed information on the levels of risk and uncertainties associated with project execution. If a project is very complex, relative to the historical background of the organization, the portfolio management tier might not have any reliable information on the 
organizational capability to implement such a project. If the prospects of a very complex project are promising, this asks for more important strategic decisions involving, among other aspects, change management and strategies for enhancing organizational capabilities.

There is always the conundrum of whether submitting projects for selection should only be done once the funding source has been identified, or whether projects are selected based on the merits of the foreseeable score and afterwards the sources are to be identified. The process presented herein asks for the former option, because the financers are preeminent stakeholders whose interests have to be part of the project intake score.

After the completion of the first two steps, a Stakeholder analysis - step (3) - is required to determine the value the stakeholders put on the alternative project outcomes and their time preference for the outcomes. As in social impact measurement methodologies [4], this step should begin with stakeholder mapping, followed by a completion of an influence/importance grid and a listing of the values of the social results/outcomes as perceived by the stakeholders.

While there is causal link between the project deliverables and the social outcomes of the project, the latter are to be assessed through instruments which allow for stakeholder appraisal of the project effects and for keeping track of misleading attribution of social improvements to project outputs. Secondly, the project outputs indicate a measurement of short term project efficiency which, without any further qualification, is not necessarily connected to long term social change. The social outcome is the main factor of the intake score, and this is undergirded by the assumption that the outcomes of the projects are exhibiting a significant strategic contribution, having already passed a strategic fit preselection. This still holds true while some outcomes might not cover social needs, but rather increase visibility helping fundraise for other projects which are social in their own turn. Assigning financial values to social outcomes serves a similar informational role as the price system does for markets, facilitating the comparisons of heterogeneous social outcomes. Stakeholder analysis is hence performed to attain consistency in systematically assigning values to social outputs and in prioritizing outcomes through expressed time preferences.

The time preferences of the stakeholders for various outcomes has to be collected in this step. Time preference is mainly a revealed expression of the social outcomes that the stakeholders would experience rather sooner than later, a consideration which is consistent with the organizational requirement to prioritize the most needed projects and to reject or postpone other projects.

We shall employ the following notations for the following sets: the stakeholders set $s_{o}$, comprised of $k$ elements $(o=1, k)$; an entity's projects set $-p_{i}$, representing a collection of $n$ projects, $(i=1, n)$; to each $i^{\text {th }}$ project will belong a set of $m$ social net result $N S R_{i j}$ results $(\mathrm{j}=1, m)$.

The equation of the net social result of a project - NSR is a summation of the difference between the monetary value of a financial proxy for the social outcomes as ascribed by the main beneficiary of the result $\left(r_{i j}\right)$ and the cost of obtaining that result $\left(c_{i j}\right)$ - as expressed in relation (1).

$$
N S R_{i}=\sum_{j=1}^{m} N S R_{i j}=\sum_{j=1}^{m}\left(r_{i j}-c_{i j}\right)
$$

The time preference of the stakeholders is expressed through a coefficient $\left(w t_{i j}\right)$. This coefficient is to be determined per each project and outcome as a weighted average (through the weights $\left.-w s_{o}\right)$ of the time preference of each stakeholder for each result $\left(w t_{i j o}\right)$ as in equation (2).

$$
w t_{i j}=\frac{\sum_{o=1}^{k} w t_{i j o}{ }^{*} w s_{o}}{\sum_{o=1}^{k} w s_{o}}
$$


The final decision on weighting the time preferences of the stakeholders and on prioritizing the outcomes is made by the nonprofit board who serves as the custodian of the endowments provided by the nonprofit founders. The share of each coefficient $\left(w s_{o}\right)$ being established according to the strategic interests of the organization. A qualitative analysis (such as the ones mentioned in the stakeholder analysis) will lead to a ranking of the importance of stakeholders, from the perspective of mission and organizational values, then each category of stakeholders will be assigned a weight of importance that can be quantitatively correlated, for example, with the financial impact of a stakeholder's behaviour for financial health. of the organization. This aspect shows that though stakeholder democratic consultancy is important, in practical matters the managerial responsibility of prioritizing interests has to be a limiting factor to absolute consensus. Some studies [17] specifically aim at devising procedures for project selection that would seek to avoid resentments among stakeholders, but the ability to diminish resentment through mathematical modelling is still questionable especially when salient social issues are discussed.

The steps leading to the fourth one, provided the informational support for the Intake assessment - step (4) which is going to be based on calculating a score function for each proposed project. For the construction of this function it is necessary to determine the way of expressing the factors, aiming at: the way of calculating the social result, the imputation of the influence of the level of deliverables efficiency, respectively a factor of efficiency of the terms. Starting with the goal of pursuing a value as high as possible of the social result, this has to be conjugated with the causal relationship between deliverables and results, which in their own turn, should take into account the efficiency of deadlines. This function of the intake score for a project $-I_{i}$ is given by the multiplication of three factors, which can be interpreted as measures of the influence of the three constraints of the projects - purpose, time, budget upon the social value of the project. The equation for $I_{i}-$ relation (3) - contains two terms already defined above $N S R_{i j}$ - implicit in relation (1) and $w t_{i j}$ obtained in relation (2).

$$
I_{i}=\sum_{j=1}^{m} N S R_{i j} * w t_{i j} * D R_{i j} * T R_{i j}
$$

The factor $D R_{i j}$ is an average of a statistical series of ratios of execution efficiency for deliverables (executed deliverables/planed deliverables) - using a series for deliverables similar to the ones needed in project $i$ to obtain the social result $j$. This factor illustrates the scope constraint and the causal contribution of the scope management to obtaining social results. Similarly, expressing the time constraint, the factor $T R_{i j}$ is an average of a statistical series of ratios of deadline efficiency, i.e. $1+$ ((execution period - planed period)/planed period), for deliverables similar to the ones needed in project $i$ to obtain the social result $j$. These two ratios where supplied in step (2). All the three factors pondering the net social result are dimensionless coefficients, hence the value of $I_{i}$ is expressed in monetary units. The budgetary constraint is already accounted for through the cost component of the net social result. One should note that the unit value of the proxy (i.e. the one ascribed to unit of outcome) is in fact a constant, only the amount of result being a control variable.

A significant issue for taking into account schedule compliance is the possibility to present the same project with alternative schedules, especially if the time preference of the most affected stakeholder is not very elastic to the prorogation of some project milestones or to the overall extension of the project duration. Generating multiple schedules for the same scope should be done by the proponents of the scope and the project charts of these duration alternatives should be prepared for the appliance of the strategic decisions procedure.

After the hierarchy of projects is established, according to the value of the intake scores, projects are chosen in increasing order until the consumption of the budget available for the strategic planning horizon. The remainder of the proposed unselected projects are postponed 
in a waiting line for future financing, if no better alternatives arise until the next decision making process. The comparison of the absolute values of the score is not to be done without reference to the whole range of projects under consideration, which might lead to project intake decisions asking for a recasting of the score estimates in the light of new projects coming under scrutiny. This remark is valuable especially if projects obtain the same intake score, but are not equivalent in terms of outcomes and schedules. Additional criteria are to be supplied for distinguishing projects with similar scores, criteria related to the influence and importance of the project stakeholders, as identified in the third step. These kind of context provide a glimpse into the irrationality (which cannot be practically ignored) of some intransient relations of equivalence between projects.

The calculation of a project intake score function such as the one proposed in equation (3) involves an inventory of procedural and organizational requirements for providing the necessary information for computing the score. Ensuring these informational requirements can be facilitated by a project management office, with an advisory role, if this departmental component is present in the organization chart of the entity. This organizational component should play a role (as already illustrated in Figure 1) in harvesting project ideas and deriving the set of generated project ideas and the set of proposed projects, primarily on the basis of the availability of the required information for the decision making process.

\section{Conclusions}

This paper offered a decision making process prototype for project intake decisions aiming at balancing the project efficiency, in terms of the triple constraint, and the need for stakeholder satisfaction. The designed four steps process manipulates project proposals through four main procedural steps, informed by endogenous and exogenous data. The last step of the project intake decision making process is founded on a project intake score, aggregating the factors of net social result (weighted by the stakeholder's time preference) and the efficiency of complying with the project contains. The theoretical contribution of the paper consists in producing an intake function and a project intake procedure that explicitly link social outcomes measurements with project efficiency criteria and stakeholder relevance criteria.

The opportunities for further research are linked to: envisioning tools for project control ensuring the projects match the criteria which has made them eligible (giving thus a feedback for improving the selection process); adjusting the process presented herein to the specifics of various organizational settings, when it comes to the organizational structure and to the available informational flows about social outcomes assessments and project reviews. The latter aspect represents one limit of the proposed process, because computing the project intake score requires the presence of archived project reviews, containing homogenous data on project delivery efficiency. The demand for data homogeneity is aptly met through applying similar metrics, budgets and work breakdown structures throughout the entire project network.

\section{References}

1. V. Tavares, Advanced models for Project Manangement (Springer Science+Business Media, New York, 1999)

2. W.W. Powell, R. Steinberg (Eds.), The Nonprofit Sector $-A$ Research Handbook, $2^{\text {nd }}$ Ed. (Yale University Press, New Haven \& London, 2006)

3. J.S. Wholey, H.P. Hatry, K.E. Newcomer (Eds), Handbook of Practical Project Evaluation, $2^{\text {nd }}$ ed. (John Wiley \& Sons, San Francisco, 2004) 
4. Nicholls J, Lawlor E, Neitzer E, Goodspeed T. A guide to Social Return on Investment URL: https://neweconomics.org/uploads/files/aff3779953c5b88d53 cpm6v3v71.pdf (2009)

5. F.M. Lacerda, C.D.P. Martens, H.M.R. de Freitas, Proj. Manag. Res. Pract. 3, 5120 http://dx.doi.org/10.5130/pmrp.v3i0.5120 (2016)

6. M.J. Worth, Nonprofit Management- Principles and Practice, $4^{\text {th }}$ ed., (SAGE, Los Angeles, 2017)

7. B. Wang, K. Narvekar, T. Nguygen, Technology Management in the IT-Driven Services (PICMET), Proceedings of PICMET 13, 401-410 (2013)

8. G. Vitner, S. Rozenes, S. Spreaggett, Int. J. Proj. Manag. 24, 323-329 (2006)

9. S. Ghorbani, M. Rabbani, Adv. Eng. Softw. 40, 9-14 (2009)

10. P. Eskerod, Int. J. Proj. Manag. 14, 61-65 (1996)

11. E.C. Too, P. Weaver, Int. J. Proj. Manag. 32, 1382-1394 (2014)

12. M. Simrad, M. Aubury, Laberge, D. (2018). Int. J. Proj. Manag. 36, 460-473 (2018)

13. S. Clegg, C.P. Killen, C. Biesenthal, S. Sankaran, S. Int. J. Proj. Manag. 36, 762-772 (2018)

14. M. Lowstedt, C. Raisanen, R. Leiringer, Int. J. Proj. Manag. 36, 889-898 (2018)

15. P.F. Drucker, Managing the Nonprofit Organization - Principles and Practices. (Harper Collins Business, New York, 2005)

16. J.L. Thompson, Strategic Management - Awarness and Change, $2^{\text {nd }}$ ed.(Chapman \& Hall, London, 1993)

17. M. Oral, O. Kettani, U. Cincar, Eur. J. Oper. Res. 130, 332-346 (2001)

18. R.L. Ackoff, J. Magdison, H.J. Addison, Idealized Design (Wharton School Publishing, New Jersey, 2006)

19. PWC. Measuring and managing total impact: A new language for bussines. URL: www.pwc.com/gx/en/sustainability/publications/total-impact-measurementmanagement/assets/pwc-timm-report.pdf (2013) 